\title{
VITAL CAPACITY, MAXIMUM BREATHING CAPACITY AND MAXIMUM BREATHING RATE IN HEALTHY MALE ADULTS
}

\author{
NOBUHIRO YAMADA* \\ Department of Public Health, Medical School of Tokyo University \\ AND \\ KICHINOSUKE TATAI $\dagger$ \\ Department of Physiological Hygiene, Institute of Public Health
}

Recently the authors have been very much interested in the study of air velocity index originately done by Gaensler (1), partly for the possibility of a theoretical study of ageing process concerning the pulmonary function, and partly for the purpose of practical application to the early diagnosis of silicatic patients and of subsequent prevention of development of silicosis which is still prevalent in Japanese industry because of its poor preventive measures. In this connection, a prerequisite to study the pulmonary function of male adults with respiratory disorders is certainly to obtain adequate standards for the vital capacity and maximum breathing capcity of normal individuals in this age group. Existing reports concering those values in Western countries may not perfectly fill this need in Japan because of several factors involved in them such as anthropometric, instrumental and occupational. This investigation has been done primarily to obtain the standards of two capacities in normal Japanese male adults.

\section{METHOD}

In an effort to obtain standards for the vital capacity and the maximum breathing capacity of healthy men, we studied 1,169 adults of different ages ranging from 20 to 80 years with various occupations. The vital capacity (V.C.) and the maximum breathing capacity (M.B.C.) were measured. The body weight and height were also measured so that both capacities could be evaluated on the basis of the body surface area (B.S.A.). The vital capacity and maximum breathing capacity were measured with YAMAKOSHI-type spirometer and RuDOLPH-type valve, respectively. The subject in an elect position was encouraged to do his utmost effort at each trial. For each capacity the largest of two trials was recorded in every subject. The vital capacity was defined as a maximal exspiration following a maximal inspiration. The period of effort for the maximum breathing capacity was 15 minutes, as it was recommended by Whittenberger (2). All ventilatory values in both capacities were corrected to body temperature $\left(37^{\circ} \mathrm{C}\right.$.). The estimate of M.B.C. was further converted to the one-minute's value multiplied by a factor of 4 .

Received for publication June 4, 1954.

* 山田進弘, †田多井吉之介 


\section{RESULTS AND DISCUSSION}

Table 1 shows the age specific values of vital capacity, maximum breathing capacity and maximum breathing rate per square meter of body surface, although, merely for the convenience, the values were divided into two age groups, namely, one of 20 to 55 years and the other of 56 to 80 years and separately analysed. In those caculation the maximum breathing rate is defined to indicate a maximum breathing capacity per liter of vital capacity.

TABLE 1. Vital Capacity, Maximum Breathing Capacity and Maximum Breathing Rate per Surface Area in Relation to Age in Years for Men

\begin{tabular}{|c|c|c|c|c|c|c|}
\hline \multirow{2}{*}{ Age, yr. } & \multirow{2}{*}{ No. } & \multicolumn{2}{|c|}{ V.C., $1 / \mathrm{m}^{2}$. } & \multicolumn{2}{|c|}{$\begin{array}{l}\text { M.B.C., } \\
1 \text { per } \mathrm{min} / \mathrm{m}^{2}\end{array}$} & \multirow{2}{*}{$\begin{array}{l}\text { M.B.R. } \\
1 \text { per } \mathrm{min} / 1\end{array}$} \\
\hline & & Mean & Std. dev. & Mean & Std. dev. & \\
\hline $20-22$ & 111 & 2.574 & 0.308 & 73.4 & 98.5 & 28.6 \\
\hline $23-25$ & 129 & 2.519 & 0.308 & 73.3 & 10.55 & 29.1 \\
\hline $26-28$ & 140 & 2.518 & 0.316 & 72.8 & 9.55 & 28.9 \\
\hline $29-31$ & 133 & 2.510 & 0.340 & 71.5 & 10.15 & 28.5 \\
\hline $32-34$ & 94 & 2.421 & 0.286 & 69.2 & 8.45 & 28.6 \\
\hline $35-37$ & 103 & 2.430 & 0.324 & 69.1 & 11.00 & 28.4 \\
\hline $38-40$ & 101 & 2.361 & 0.291 & 67.7 & 9.85 & 28.7 \\
\hline $41-43$ & 76 & 2.311 & 0.340 & 66.1 & 9.65 & 28.6 \\
\hline $44-46$ & 78 & 2.274 & 0.268 & 64.1 & 10.05 & 28.2 \\
\hline $47-49$ & 43 & 2.188 & 0.321 & 61.9 & 10.98 & 28.3 \\
\hline $50-52$ & 41 & 2.198 & 0.254 & 59.2 & 9.90 & 26.9 \\
\hline $53-55$ & 25 & 2.140 & 0.252 & 58.3 & 9.32 & 27.2 \\
\hline $56-60$ & 18 & 2.051 & 0.397 & 56.5 & 13.20 & 27.6 \\
\hline $61-65$ & 37 & 1.849 & 0.373 & 51.0 & 18.26 & 27.0 \\
\hline $66-70$ & 16 & 1.767 & 0.437 & 43.1 & 10.09 & 24.3 \\
\hline $71-75$ & 18 & 1.624 & 0.463 & 39.6 & 19.66 & 24.4 \\
\hline $76-80$ & 6 & 1.510 & 0.358 & 33.4 & 9.40 & 22.3 \\
\hline
\end{tabular}

These two respiratory capacities and the rate tend to decrease gradually as the age advances. Figure 1 shows clearly this evidence. The vital capacity falls more lineally than the maximum breathing capacity. The decline in the maximum breathing capacity appears to be accelerated after the sixth decade. This influences the shift in the maximum breathing rate. It is apparent that the muscle power plays an important role in the respiratory capacity. However, it seems not to fully explain the cause of a marked decline in the maximum breathing rate after the sixth decade, since the decline of muscle power occurs obviously during the period of the third decade when the body structure reaches in its full maturity, as evidenced by maximum grip strength and grip-strength endurance $(3,4)$. The loss of elasticity pertaining to the respiratory function (e.g., in the thorax and alveolar tissues) will be also responsible for the decline of the maximum breathing rate, even it is not so for the decrease of the vital capacity. This agrees with the finding that in patients suffering from emphysema the vital capacity has been less impaired than the maximum breathing capacity (1) and the emphysema itself is one of the most common disorders in the aged population. Therefore, it is suggested that the patients or seemingly healthy 
workers with silicosis accompanied by emphysema may be detectable without any radiological evidence, so far as their maximum breathing rates are subnormal.

Gaensler has, indeed, emphasized the possible role of his air velocity index in detecting emphysema (1). In order to know the normal value at the given age, this investigator used the regression formulae reported by Boldwin et al. (5) both for the vital capacity and for the maximum breathing capacity. However, it was doubtful whether his formulae might be rightfully applied to Japanese healthy males. One of the authors, therefore, tried to find out the two

FIG. 1. Vital capacity, maximum breathing capacity and maximum breathing rate per body surface area in relation to age in years for men.

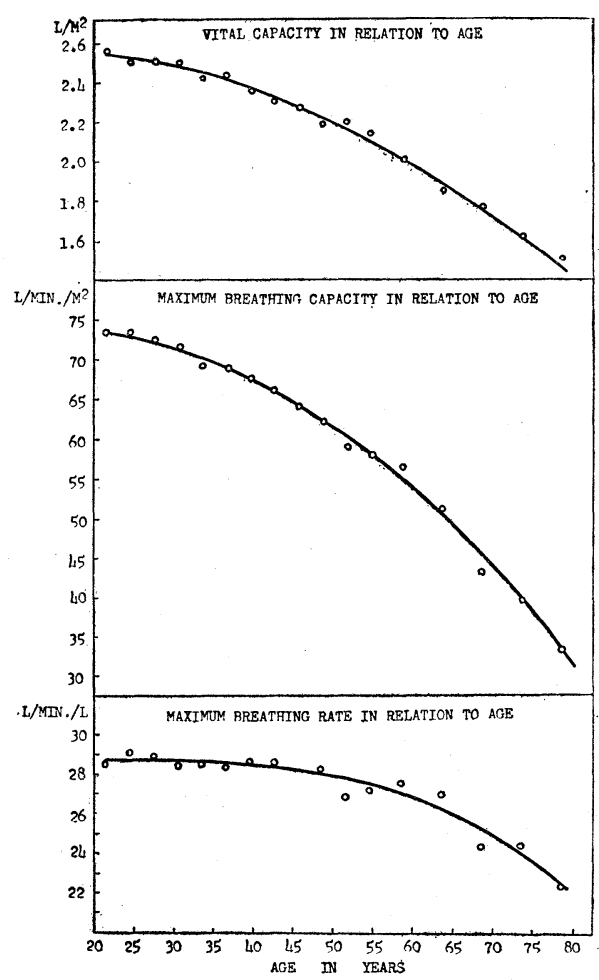

regression formulae applicable to the Japanese. Thus, the following formulae for the vital capacity as well as for the maximum breathing capacity have been recently contrived for two age groups ranging from 20 to 55 years (6) and from 56 to 80 years (7).

1. For the age group of 20 to 55 years.

$$
\begin{gathered}
\text { V.C. }(1 .)=[2.848-(0.0133 \times \mathrm{AGE})] \times \text { B.S.A. }\left(\mathrm{m}^{2} .\right) \\
\text { M.B.C. }(1 / \mathrm{min} .)=[88.01-(0.530 \times \mathrm{AGE})] \times \text { B.S.A. }\left(\mathrm{m}^{2} .\right)
\end{gathered}
$$

2. For the age group of 56 to 80 years.

$$
\begin{aligned}
& \text { V.C. }(1 .)=[3.456-(0.025 \times \text { AGE })] \times \text { B.S.A. }\left(\mathrm{m}^{2} .\right) \\
& \text { M.B.C. }(1 / \mathrm{min} .)=[107.8-(0.932 \times \text { AGE })] \times \text { B.S.A. }\left(\mathrm{m}^{2} .\right)
\end{aligned}
$$

Mainly for the simplicity of practical use, regression lines were preferred to the regression curve which appeared more reasonable to yield a complete formula including all age groups from 20 to 80 years. In order to evaluate the vital capacity, moreover, the body surface area was selected for the unit in his study in spite of the general use of body height, since it was found that the body surface area was more highly correlated to the vital capacity than the simple height. 
The regression formula for calculation of predicted values of maximum breathing capacity which was applied to by Gaensler was $[86.5-(0.522 \times$ AGE $)]$ $\times$ B.S.A. $\left(\mathrm{m}^{2}\right.$.) for males (5). This formula is approximately similar to our formula for the age group of 20 to 55 years, i.e., $[88.01-(0.530 \times \mathrm{AGE})] \times$ B.S.A. $\left(\mathrm{m}^{2}.\right)$. Therefore, the pulmonary function is unlikely to differ greatly with races.

A table of the coefficients of correlation due to five attributes is presented in regard to two kinds of age groups, that is, the younger and the elder group (table 2). In the table there are several points worthy of adding here: The value of negative correlation of age to the vital capacity or to the maximum breathing capacity was not much deviated in two age groups, while that of the positive correlation of the body surface area to the vital capacity or to the maximum breathing capacity was remarkably reduced with the advance of age; in the advanced age group the correlation between V.C. and M.B.C. was also lower than in the younger one $(+0.420 \mathrm{vs} .+0.501)$. The primary cause of the latter evidence may be essentially due to the above-mentioned fact that after the sixth decade the maximum breathing capacity decreases more rapidly than the vital capacity.

TABLE 2. Correlation Coefficients of Five Attributes in Healthy. Men with Age from 20 to 80 Years

\begin{tabular}{l|c|c|c|c}
\hline \hline & \multicolumn{2}{|c|}{$\begin{array}{c}\text { The younger group with } \\
\text { age of } 20 \text { to } 55 \text { years }\end{array}$} & \multicolumn{2}{c}{$\begin{array}{c}\text { The older group with } \\
\text { age of } 56 \text { to } 80 \text { years }\end{array}$} \\
\cline { 2 - 5 } & V.C. & M.B.C. & V.C. & M.B.C. \\
\hline Age & -0.336 & -0.368 & -0.356 & -0.376 \\
Hight & +0.471 & +0.314 & +0.336 & +0.123 \\
Weight & +0.423 & +0.239 & +0.310 & +0.188 \\
B.S.A. & +0.525 & +0.315 & +0.354 & +0.167 \\
V.C. & - & +0.501 & - & +0.420 \\
\hline
\end{tabular}

The nature of the maximum breathing rate is more or less similar to that of the air velocity index; the former is defined as a rate of measured M.B.C./ measured V.C., while the latter is an index of measured M.B.C./predicted M.B.C. divide by measured V.C./predicted V.C. However, the former is simpler than the latter, because there is no need for prediction in it. For the practical use during screening examination in industry, therefore, the air velocity index is likely to be substituted by the maximum breathing rate.

\section{SUMMARY AND CONCLUSION}

The vital cabacity and the maximum breathing capacity have been studied in 1,169 healthy individuals of different ages from 20 to 80 years in connection with an interest in the air velocity index.

The results show that the values of vital capacity, maximum breathing capacity and maximum breathing rate per square meter of body surface are, to some extent, decreased in accordance with the advent of age, although the maximum breathing rate appears most suitable to evaluate a failure in the ventilatory function associated with emphysema or silicosis. 
The coefficients of correlation among various attributes measured in this study also support this view obtained from the age specific trend curve of the maximum breathing rates. Thus the maximum breathing rate certainly bears a practical significance in periodical examinations in industry where silicatic workers should be eliminated and compensated. Even the apparently healthy people may have greatly lost their pulmonary capacity reserved for the maximal effort, when they reach to the sixth decade. From this evidence, it is correspondingly suggested that after the sixth decade the streneous muscular effort should be avoided to prevent the parenchymatous tissue degeneration occasionally resulted from hypoxia of any vitally important organ.

\section{ACKNOWLEDGEMENT}

The authors gratefully acknowledge valuable suggestions given by Prof. J. L. Whittenberger of the School of Public Health, Harvard University. Acknowledgement is also given to Mr. S. Ogawa in our laboratory for his devoted assistance in this study.

This work has been partly supported by the grant of the Ministry of Labor.

\section{REFERENCES}

1. GAENSler, E. A. Air velocity index: A numerical expression of the functionally effective portion of ventilation. Amer. Rev. Tuberc. 62: 17, 1950.

2. Whittenberger, J. L. Personal communication.

3. Burke, W. E., Tuttle, W. W., Thompson, C. W., Janney, C. D., and Weber, R. J. The relation of grip strength and grip-strength endurance to age. J. Appl. Physiol. 5: 628, 1953.

4. IshikAWA, T., TATAI, K., AND YAMADA, N.: Grip strength of male adults. Jap.J. Publ. Health. to be published.

5. BALDWIN, E. DE F., COURNAND, A., AND RICHARDS, D. W., Jr.: Pulmonary insufficiency. I. Physiological classification, clinical methods of analysis, standard values in normal subjects. Medicine $27: 243,1948$.

6. YAMADA, N.: Vital capacity and maximum breathing capacity in normal male adults. Jap. J. Physical Fitness 4: 1, 1954.

7. YAMADA, N. Studies on vital capacity and maximum breathing capacity in the aged. ibid. $4: 9,1954$. 